Rev. Elet. em Gestão, Educação e Tecnologia Ambiental (e-ISSN: 2236-1170)

\title{
MULTIPLICAÇÃO DE EXPLANTES NO CULTIVO IN VITRO DE ACACIA MEARNSII DE WILD.
}

\author{
MULTIPLICATION OF EXPLANTS IN VITRO CULTURE OF \\ ACACIA MEARNSII DE WILD.
}

\begin{abstract}
Eliara Marin Piazza, Ana Paula Jung, Roselene Marostega Felker, Andréa Cristina Dörr
\end{abstract}
http://dx.doi.org/10.5902/223611708733

\begin{abstract}
RESUMO
A Acacia mearnsii De Wild., popularmente conhecida como acácia-negra, ocupa a terceira colocação entre as espécies florestais mais plantadas no Brasil, com objetivo econômico voltado para extração de tanino, celulose, produção de energia e de carvão. Dentro deste contexto o presente trabalho objetivou realizar a multiplicação in vitro de explantes de Acacia mearnssi De Wild, introduzidos no meio de cultura MS a 1\% de BAP. Para a etapa de multiplicação foram utilizados como fonte de explantes segmentos nodais e de hipocótilo. Em todas as concentrações testadas houve o desenvolvimento de gemas axilares, com pelo menos uma brotação por segmento nodal, sendo que o número máximo foi de três brotações, portanto, ocorreu a interação entre o meio e as concentrações utilizadas. Dessa forma, conclui-se que, a composição e as concentrações aplicadas foram apropriadas para esta espécie, pois o regulador de crescimento utilizado na cultura in vitro, induziu o surgimento de raízes adventícias, iniciação de calos, alongamento e a divisão celular.
\end{abstract}

Palavras-chave: acácia-negra, brotações, espécie florestal

\begin{abstract}
The Acacia mearnsii De Wild., Popularly known as black wattle, occupies the third place among species grown in Brazil, aiming toward economic extraction of tannin, pulp production and energy coal. Within this context, this work aims to perform the in vitro multiplication of explants of Acacia mearnssi De Wild, introduced in the culture medium at $1 \%$ BAP. For step of multiplication were used as explants source nodes and hypocotyl. At all concentrations tested there was the development of axillary buds, with at least one sprout per nodal segment, and the maximum number was 3 shoots, the interaction occurring between the middle and the concentrations used. Thus, it is concluded that the composition and concentrations used were appropriate for this species as the plant growth regulator used in vitro culture, induced the appearance of adventitious roots, callus initiation, elongation and cell division.
\end{abstract}

Keywords: black wattle, forest species, shoots 
PIAZZA, et all, v(11), no 11, p. 2321-2326, JUN, 2013.

REGEXATFSM

Rev. Elet. em Gestão, Educação e Tecnologia Ambiental (e-ISSN: 2236-1170)

\section{INTRODUÇÃO}

A Acacia mearnsii De Wild., popularmente conhecida como acácia-negra, ocupa a terceira colocação entre as espécies florestais mais plantadas no Brasil, perdendo apenas para as espécies dos gêneros Eucalyptus e Pinus.

Originária da Austrália, a acácia-negra é plantada comercialmente no Estado do Rio Grande do Sul e constitui numa importante espécie florestal no estado, cuja área atual plantada é superior a 160 mil ha, distribuída principalmente em minifúndios (MAESTRI et al., 1987).

A espécie possui ampla utilização, tanto da casca quanto da madeira. O principal objetivo da introdução da espécie no Brasil foi para extração de tanino presente na casca, muito utilizado para curtimento de couro. A madeira era considerada um produto secundário, aproveitada para produção de energia e carvão. Atualmente, a madeira de acácia-negra é utilizada para produção de celulose, por apresentar um teor de lignina inferior às espécies tradicionalmente destinadas a esse fim.

Os primeiros plantios florestais realizados no Brasil com acácia-negra foram efetuados com sementes provenientes da época da introdução da espécie, sem controle genético e ainda com pouca variabilidade. Assis et al. (1993), afirma que devido as plantações serem oriundas de sementes, existe uma carência de técnicas de propagação vegetativa aliadas ao melhoramento genético limitado o uso deste gênero.

Com o intuito de aumentar a produtividade das florestas de $A$. mearnsii, a propagação clonal de indivíduos superiores, selecionados dentro de um programa de melhoramento genético vêm sendo desenvolvida através da cultura de tecidos (BECK et al., 2000; VENGADESAN et al., 2002).

A técnica do cultivo in vitro para de o gênero Acacia tem sua problemática relatada acerca da definição do meio básico a ser utilizado e o balanço adequado entre auxinas e citocininas, principalmente na etapa de multiplicação de gemas, alem de ser uma espécie de difícil micropropagação devido à pequena capacidade de multiplicação e desenvolvimento de gemas.

Dentro desse contexto, o presente trabalho objetivou realizar a multiplicação in vitro de explantes de Acacia mearnssi De Wild, introduzidos no meio de cultura MS (MURASHIGE e SKOOG, 1962) a 1\% de 6-benzilaminopurina (BAP).

\section{METODOLOGIA}

O experimento foi realizado no Laboratório de Biotecnologia e Melhoramento Genético Florestal do Departamento de Engenharia Florestal, da Universidade Federal de Santa Maria, campus do Centro de Educação Superior Norte - RS. 


\section{REGETHFSM}

PIAZZA, et all, v(11), no 11, p. 2321-2326, JUN, 2013.

Rev. Elet. em Gestão, Educação e Tecnologia Ambiental (e-ISSN: 2236-1170)

Para a etapa de multiplicação foram utilizadas como fonte de explantes, segmentos nodais, com aproximadamente $2 \mathrm{~cm}$ de comprimento, contendo duas gemas axilares, e ainda segmentos de hipocótilo de $1 \mathrm{~cm}$, obtidos de plântulas oriundas do próprio local. Ápices caulinares foram excisados de plantas matrizes, com aproximadamente seis meses de idade, da população proveniente de um programa de melhoramento do campus, disponível no jardim clonal do curso de engenharia florestal.

Para controle da assepsia os explantes foram imersos em etanol 70\%, por 1 minuto seguido de hipoclorito de sódio a $2 \%$ de cloro ativo por 20 minutos, e inoculados em câmara de fluxo laminar.

Os segmentos nodais foram dispostos verticalmente, enquanto os de hipocótilo foram colocados horizontalmente no interior de um recipiente de conserva, contendo aproximadamente $40 \mathrm{ml}$ de meio de cultura, os quais foram tampados com papel alumínio e esterilizados em autoclave por 15 minutos à temperatura de $120^{\circ} \mathrm{C}$ e $1 \mathrm{~atm}$ de pressão.

Testou-se os meios de cultura MS (MURASHIGE e SKOOG, 1962), MS suplementado com 0,5mgL-1 e 0,75mgL-1 de citocinina BAP (6- benzilaminopurina) acrescidos de $30 \mathrm{gL}-1$ de sacarose e 6 gL-1 de ágar com pH ajustado para 6,5 antes da esterilização.

Após a inoculação a cultura foi mantida em sala de crescimento sob controle de temperatura a $25 \circ \mathrm{C}( \pm 2 \circ \mathrm{C})$ e fotoperíodo de 16 horas sob intensidade luminosa de aproximadamente 2000 lux, fornecida por lâmpadas fluorescentes branco-frias.

O delineamento experimental utilizado foi o inteiramente casualizado com três tratamentos, seis repetições e três frascos por repetição, sendo a mesma constituída pelo meio de cultura MS contendo segmentos nodais e de hipocólito. Aos 30 dias a variável observada foi à ocorrência, ou não, do desenvolvimento de gemas axilares, explantes que se mantiveram vivos, e o surgimento dos processos da organogênese.

\section{RESULTADOS E DISCUSSÃO}

De acordo com dados preliminares, evidencia-se que o meio de cultura utilizado promoveu a multiplicação dos explantes de acácia negra, pois, em todas as concentrações testadas houve o desenvolvimento de gemas axilares, com pelo menos uma brotação por segmento nodal. O número máximo foi de três brotações, portanto, ocorreu interação entre o meio e as concentrações utilizadas comprovando a existência de uma resposta diferenciada a multiplicação em relação às doses aplicadas. Esse resultado obtido corrobora com o estudo realizado por Assis et al. (1993), que obteve resultados satisfatórios com a microprogação da espécie a diferentes meios de cultura MS, em que houve crescimento e proliferação de gemas axilares.

A aplicação do método de cultura in vitro, foi eficiente quanto aos requerimentos nutricionais dos tecidos e células da espécie. Os dois fatores que determinaram o sucesso nesta 


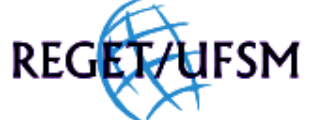

PIAZZA, et all, v(11), no 11, p. 2321-2326, JUN, 2013.

Rev. Elet. em Gestão, Educação e Tecnologia Ambiental (e-ISSN: 2236-1170)

cultura foram a boa qualidade na origem do explante e o meio nutritivo composto por elementos essenciais ao desenvolvimento do processo de organogênese, que é importante para o gênero Acacia.

A escolha da composição e da concentração de um modo geral, também foi realizada de forma exata para a espécie em questão e para o propósito da cultura. O meio de Murashige e Skoog, 1962 (MS), apresentou surgimento de gemas axilares pelo menos com numero mínimo de brotos em todas as repetições desta concentração $(0,0 \mathrm{mgL}-1)$, isto deve se ao fato do meio conter quantidades mais baixas de sais minerais, o que parece ser preferido por este gênero.

Obtiveram-se valores dos parâmetros analisados a partir da avaliação parcial do experimento em relação às concentrações de BAP na qual os explantes foram submetidos. Os resultados desses parâmetros podem ser visualizados na Tabela 1.

Tabela 1. Valores médios do subcultivo de brotos de Acacia mearnsii De Wild nas concentrações a qual os explantes foram submetidos. $\mathrm{Ti}=$ Tratamento; $\% \mathrm{EV}=$ Porcentagem de explantes vivos; $\%$ $\mathrm{EB}=$ Porcentagem de explantes brotados e $\% \mathrm{EC}=$ Percentagem de explantes com calo Médias seguidas pela mesma letra não diferem estatisticamente pelo Teste de Tukey, a nível de $5 \%$ de probabilidade.

\begin{tabular}{|c|c|c|c|}
\hline Ti mg.l-1 & $\%$ EV & $\%$ EB & $\%$ EC \\
\hline 0,00 & $100.00 \mathrm{a}$ & $100.00 \mathrm{a}$ & $29.17 b$ \\
\hline 0,50 & $100.00 \mathrm{a}$ & $100.00 \mathrm{a}$ & $48.57 \mathrm{ab}$ \\
\hline 0,75 & $86.51 \mathrm{~b}$ & $86.51 \mathrm{~b}$ & $67.62 \mathrm{a}$ \\
\hline $\mathbf{F}$ & 8.05 & 8.05 & 9.34 \\
\hline
\end{tabular}

A concentração de BAP $0,5 \mathrm{mgL}-1$ junto ao meio de cultura MS, induziu o surgimento do número máximo de brotações e obteve um bom desempenho no desenvolvimento de calosidade. $O$ meio MS acrescido de BAP $0,75 \mathrm{mgL}$, foi o melhor tratamento promotor do surgimento de calos, pois obteve a maior média, portanto, mais eficiente em relação as demais dosagens. Tais resultados vão ao encontro com a pesquisa de Borges et al. (2004) para Acacia mearnsii, em que as calosidades tiveram maiores dimensões principalmente nos tratamentos com concentrações elevadas de citocinina.

De um modo geral, o regulador testado (BAP) obteve um índice bom no desenvolvimento de gemas axilares. Essa substância trata-se de uma das citocininas de menor custo muito eficaz na multiplicação de diversas espécies. Estudos realizados por Grattapaglia \& Machado (1998), explicam que a eficiência da citocinina pode estar na capacidade dos tecidos vegetais em metabolizar os hormônios naturais mais rapidamente do que os sintéticos. Segundo Disarz e Corder (2009), em seu 


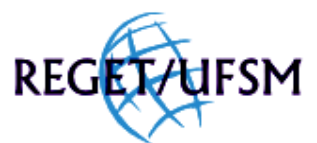

PIAZZA, et all, v(11), no 11, p. 2321-2326, JUN, 2013.

Rev. Elet. em Gestão, Educação e Tecnologia Ambiental (e-ISSN: 2236-1170)

trabalho o meio MS promoveu a maior formação de gemas e folhas em explantes de $A$. mearnsii. A redução de $25 \%$ na concentração dos macronutrientes do meio MS combinado com a adição de 1 g.L 1

de carvão ativado promoveu as maiores taxas de multiplicação e possibilitou o enraizamento e aclimatação da espécie.

Durante o preparo do meio de cultura o pH da solução foi ajustado corretamente, e com isso, o ágar que é um composto muito importante para dar consistência a esse preparo, assim servindo de suporte as culturas, tornou-se eficiente na solidificação deste meio. Conforme Tranthanh Van (1980) o pH induz mudanças de permeabilidade das membranas influenciando na absorção e utilização de certos compostos pelas células, como por exemplo, no caso de reguladores de crescimento e de nitrogênio que são liberados pelo amônio influenciando na solidificação.

A quantidade do meio produzido demonstrou-se satisfatória para a utilização no cultivo dos explantes da espécie. Segundo Murashige (1977), a quantidade de meio no frasco de cultura pode influenciar o desenvolvimento dos explantes e na taxa de multiplicação, sendo que a quantidade deve ser proporcional ao tamanho e número de explantes, como também ao tamanho do frasco de cultura.

As etapas de esterilização dos meios de cultura através da autoclavagem demonstraram se adequadas, pois não ocorreu contaminações. Condições assépticas adequadas são fundamentais para o estabelecimento da cultura in vitro, sendo que qualquer descuido com recipientes contaminados pode comprometer o restante do cultivo que se encontram livre de microorganismos.

\section{CONCLUSÕES}

A cultura de tecidos de acácia-negra, utilizando segmentos nodais e de hipocótilo pode ser desenvolvida com o uso do meio MS, tornando assim, imprescindível a realização de demais estudos para verificar os níveis hormonais adequados para a espécie. O processo de ajuste do protocolo com o meio de cultivo supriu as necessidades da espécie tornando-a propícia a multiplicação.

Diante disto, conclui-se que, a composição e as concentrações aplicadas foram às apropriadas para esta espécie, pois o regulador de crescimento utilizado na cultura in vitro, induziu o surgimento de raízes adventícias, iniciação de calos, alongamento e a divisão celular. Sendo assim, é possível à multiplicação por via assexuada, resultando em um maior número de descendentes que podem ser multiplicados sem modificar sua estrutura genética, além de manter características desejáveis e ainda proporcionar uma produção mais precoce diminuindo o tempo necessário a liberação de uma nova cultivar.

\section{REFERÊNCIAS BIBLIOGRÁFICAS}

ASSIS, T. F. et al. Propagação vegetativa da Acacia mearnsii De Wild. In: $7^{\circ}$ Congresso Florestal Panamericano e $1^{\circ}$ Congresso Florestal Brasileiro, 1993, Curitiba. Anais. Curitiba: SBS/SBEF, 1993. p. 150-152. 


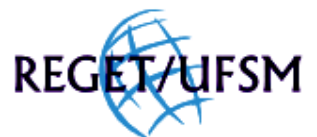

PIAZZA, et all, v(11), no 11, p. 2321-2326, JUN, 2013.

Rev. Elet. em Gestão, Educação e Tecnologia Ambiental (e-ISSN: 2236-1170)

BECK, S. L. et al. Meristem culture of Acacia mearnsii. Plant Growth Regulation, v. 32, n. 1, p. 49-58, 2000.

BORGES, N. J. et al. Multiplicação in vitro de gemas axilares de Acácia-negra (Acacia mearnsii De Wild.). Revista Árvore, v. 28, n. 4, p. 493-498, 2004.

DIASARZ, R.; CORDER, M. P. M. Multiplicação de gemes axilares de Acacia mearnsii de Wild. Sob diferentes meios de cultura. Revista Árvore, v. 33 n. 4, 2009.

GRATTAPAGLIA, D.; MACHADO, M. A. Micropro-pagação. In: TORRES, A. C.; CALDAS, L. S.; BUSO, J. A. Cultura de tecidos e transformação genética de plantas. Brasília: EMBRAPA-SPI/EMBRAPA-CNPH, v. 1, p. 183-260, 1998.

MAESTRI, R. et al. Análise da adubação fosfatada na produção física e econômica da acácia-negra (Acacia Mearnsii De Wild). Boletim de Pesquisa Florestal, n.14, p.39-53, 1987.

MURASHIGE, T. Clonal crops through tissue culture. In: BARZ, W.; REINHARD, E.; ZENCK, M. H. eds. Plant tissue culture and its biotechnological application, New York, Springer-Verlag, p. 392-406, 1977.

MURASHIGE, T.; SKOOG, F. A revised medium for rapid growth and bioassays with tobacco tissue cultures. Physiologia Plantarum, v.15, n.3, p.473-497, 1962.

TRAN THANH VAN, K. Control of morfogenesis by inherent and exogenously applied factors in thin cell layers. Revista Cytol, 11A, p. 175-194, 1980.

VENGADESAN, G. et al. In vitro propagation of Acacia species - A review. Plant Science, v.163, n.4, 2002. 